\title{
AN EXPERIMENTAL INVESTIGATION ON THE PHOTOCATALYTIC BEHAVIOR AND DURABILITY ASPECTS OF NANO MAGNESIUM OXIDE INCORPORATED CEMENT COMPOSITE
}

\author{
Chrysolite Mercy J \\ Student at Mepco Schlenk Engineering College, \\ Sivakasi, Tamil Nadu, India \\ Dr. Prabavathy S \\ Senior Professor, Head of Department of Civil Engineering, \\ Mepco Schlenk Engineering College, Sivakasi, Tamil Nadu, India
}

\begin{abstract}
In this work, the nano magnesium oxide was incorporated in the cement to study about its photocatalytic property. GGBS was partially replaced in cement by $30 \%$ to impart durability. The photocatalytic property was studied for organic pollutant as well as gaseous pollutant. The organic pollutant used to study about self-cleaning property is methyl violet dye solution and the gaseous pollutant used was vehicular emission to study about the degradation of $N O_{X}$ gases. Then the strength and durability aspects of the cement composite was studied from the mortar cubes and tiles specimens. The results show good with the photocatalytic property and durability of incorporated cement composite.
\end{abstract}

Keywords: Nano magnesium oxide, photocatalytic property, methyl violet dye solution, $\mathrm{NO}_{\mathrm{X}}$ degradation, self-cleansing, photocatalytic tile

Cite this Article: Chrysolite Mercy J and Prabavathy S, An Experimental Investigation on the Photocatalytic Behavior and Durability Aspects of Nano Magnesium Oxide Incorporated Cement Composite, International Journal of Civil Engineering and Technology (IJCIET), 12(4), 2021, pp. 30-49.

https://iaeme.com/Home/issue/IJCIET?Volume=12\&Issue $=4$

\section{INTRODUCTION}

With the increasing air pollution by emissions from industries and vehicles, major risks are arising to human health. The gases that cause the air pollution is Nitrogen oxide $\left(\mathrm{NO}_{\mathrm{x}}\right)$, Volatile Organic Compounds (VOC), Carbon dioxide $\left(\mathrm{CO}_{2}\right)$, Sulphur oxide $\left(\mathrm{SO}_{\mathrm{x}}\right)$ etc. Hence, various technologies are adopted to reduce the pollution. Among them, the use of some nano materials 
in building materials because of its photocatalytic property became a promising technology in mitigating the air pollution with the generation of holes and electron pair and by redox reaction with the solar irradiation. More than 40 years has passed with the discovery of photocatalytic property of titanium oxide, researchers are still aiming for the use of photocatalytic materials in an efficient manner. The most widely studied material for photocatalytic property is titanium dioxide in both micro and nano sized particle. The titanium oxide is used because it is a semiconductor catalyst which has a band gap greater than or equal to $3.2 \mathrm{eV}$ [1]. Studies on micro titanium dioxide particle shows that it shows good photocatalytic property but the strength of the concrete decreased with the increasing amount of titanium dioxide particle. Apart from titanium oxide, there are few nano materials such as nano zinc oxide and nano magnesium oxide perform photocatalytic property. V.P Singh, Kumar Sandeep et.al., has studied about the Photocatalytic, hydrophobic and antimicrobial characteristics of $\mathrm{ZnO}$ nano needle embedded cement composites. They studied the photocatalytic property of $\mathrm{ZnO}$ nano needles by using Rhodamine $6 \mathrm{G}$ dye solution. $\mathrm{ZnO}$ is added as a filler by $5 \%, 10 \%$ and $15 \%$ by weight. The results stated that the photocatalytic property increases with the increase of zinc Oxide nano particle. The zinc oxide nano needles show anti-microbial activity even in dark and light conditions. The zinc oxide nano needle shows good functional properties with the increase of nano particles [2]. Ming Zhi Guo and Chi Sun Poon has studied about the photocatalytic removal of $\mathrm{NO}_{\mathrm{X}}$ with white cement over ordinary cement. They observed that compared to WC, OPC shows lesser photocatalytic property. Due to the presence of $\mathrm{Fe}_{2} \mathrm{O}_{3}$, OPC shows poor performance because of stronger light absorption and lower charge separation. The $\mathrm{NO}_{\mathrm{x}}$ removal was studied using a reactor for hardened cement paste. The light absorption capacity of different samples was studied using UV-Spectroscopy analysis. Charge separation and transportation of different samples were studied by Electrochemical Impedance Spectroscopy (EIS Spectroscopy). After 1 day curing the effect of $\mathrm{NO}_{\mathrm{X}}$ removal rate was twice for WC compared to OPC. They observed that the curing age did not affect the $\mathrm{NO}_{\mathrm{X}}$ removal ability [3]. Jun Chen, Shi-cong Kou has studied about the photocatalytic materials on the nitrogen oxide and toluene removal and stated that the degradation of toluene by the titanium oxide modified concrete surface is not identified. However, it is effective in the removal of NO gases and shows good discoloration of the dye with the exposure to sunlight [4]. Binas and Papadaki et.al., has studied about the effect of substrate on the photocatalytic material. Among plywood, glass and gypsum, the cement-based coating on glass shows better results [5]. Lu Yang, Fazhon Wang et.al., has studied about the influence of porosities and loading levels of $\mathrm{TiO}_{2}$ on the photocatalytic degradation of gaseous benzene. The results suggested that with the increasing $\mathrm{TiO}_{2}$ loading condition, there is an increase in the photocatalytic performance of the material till it reaches an optimum loading concentration of $1 \mathrm{~g} / \mathrm{L}$. With the increased addition of $\mathrm{TiO}_{2}$ particles, they start agglomerated and results in poor photocatalytic performance. In case of porosity, with the increase rate of porosity the removal rate of gaseous benzene got increased to some level and then decreases. The low-density cement substrates help in good dispersion of the loaded $\mathrm{TiO}_{2}$ particles which high density substrates results in agglomeration of particles and hindering the ways to activate the electron-hole pair generation [7]. Azam Yousefi, Ali Allahverdi et.al., has studied about the effective dispersion of nano $\mathrm{TiO}_{2}$ particle for the enhancement of photocatalytic property. Prior to mixing it with cement, it is allowed to get disperse in the lime solution to avoid agglomeration. Due to the proper dispersion of the particle and adding it in cement, decreases the agglomeration of the particles and also increases their photocatalytic performance [8].

Apart from titanium oxide in both micro and nano scale, nano zinc oxide and nano magnesium oxide shows good photocatalytic property. Researches have done on the photocatalytic property of those nano materials and stated that it shows good photocatalytic property with the discoloration of dye solution. Shravana Kumar K.N and Nagaswarupa H.P 
et.al., has studied about the photocatalytic behavior of nano $\mathrm{ZnO}$ and $\mathrm{MgO}$. The $\mathrm{ZnO}$ and $\mathrm{MgO}$ nano particles were synthesized by the simple and low-cost combustion method. The discoloration of the dye was studied for methyl blue and methyl orange dye solution. Both nano $\mathrm{ZnO}$ and nano $\mathrm{MgO}$ shows about greater than $90 \%$ photocatalytic activity in the degradation of both methyl blue and methyl orange dye solution [6]. Sivakumar P, Lavanya R et.al., has studied on the photocatalytic behavior of $\mathrm{MgO} / \mathrm{Ag}$ nanocomposite against textile dye. Here the photocatalytic property was studied for nano $\mathrm{MgO}$ and $\mathrm{MgO} / \mathrm{Ag}$ nanocomposite and found that the nanocomposite shows better results with the $\mathrm{MgO}$ nano particle. Since there are large number researches on the photocatalytic property of nano materials such as nano $\mathrm{ZnO}$ and nano $\mathrm{MgO}$, only few researches were done on the photocatalytic property of the nano material incorporated cement-based composites with these nano materials [6]. Yajun Zheng, Liyun Cao et.al., has studied about the flower like magnesium oxide nano particle for its photocatalytic property and stated that the flower like micro sized particles performed well in compared to other shapes such as spherical, rod-shaped etc. It has good reusability which can withstand up to five cycles [10]. Studies stated that nano magnesium oxide when added in cement up to a level gives increases in strength but with the increase addition of nano magnesium oxide results in the decrease of strength. The addition of $2 \%$ to $4 \%$ of nano magnesium oxide shows good compressive strength. The addition of nano magnesium oxide in cement also increases the fire resistivity of the specimen [9].

Hence in this work, the nano magnesium oxide was incorporated in the cement for varying percentages. The photocatalytic property of the material is studied for both the organic pollutant and gaseous pollutant. The organic pollutant used is methyl violet dye solution and the gaseous pollutant used is vehicular emission. Then the durability aspects of the incorporated cement composite were checked by various studies. The nano material incorporated mortar cubes was studied for compressive strength, water absorption, RCPT test, and acid attack test. The tile specimen was casted and studied for its wear and tear resistance and flexural strength. Then the results were compared with the conventional specimen.

\section{EXPERIMENTAL PROGRAMME}

\subsection{Materials}

OPC 53 grade cement confirmed to IS 8112-1989 obtained from Ultratech cement Ltd, at Tamil Nadu in India. GGBS is used as a partial replacement of cement up to $30 \%$ to provide durability. Natural river sand of size $4.75 \mathrm{~mm}$ under the zone II is used in this research. The fineness modulus of the fine aggregate is about 2.637. The nano magnesium oxide is of size 30$40 \mathrm{~nm}$ is used. The wavelength and the energy gap of nano magnesium oxide was found to be $550 \mathrm{~nm}$ and $5.82 \mathrm{eV}$ respectively. The specific gravity of cement and GGBS used is found to be 3.12 and 2.95 respectively. The organic pollutant used is methyl violet dye solution. The gaseous pollutant used is vehicular emission. The particle size distribution and physical properties of fine aggregate was shown in Table I. The Chemical composition of OPC and GGBS was shown in Table II. 
Table 1 Particle size distribution and physical properties of fine aggregate

\begin{tabular}{|lc|}
\hline Sieve size (mm) & \% passing \\
$4.75 \mathrm{~mm}$ & 96 \\
$2.36 \mathrm{~mm}$ & 93.9 \\
$1.18 \mathrm{~mm}$ & 62 \\
$600 \mu \mathrm{m}$ & 47.9 \\
$300 \mu \mathrm{m}$ & 7 \\
$150 \mu \mathrm{m}$ & 2.1 \\
Fineness modulus & 2.637 \\
\hline
\end{tabular}

Table 2 Chemical composition of OPC and GGBS

\begin{tabular}{|llc|}
\hline Chemical composition & 0PC & GGBS \\
$\mathrm{SiO}_{2}$ & 22.18 & 6.857 \\
$\mathrm{Al}_{2} \mathrm{O}_{3}$ & 5.95 & 0.598 \\
$\mathrm{Fe}_{2} \mathrm{O}_{3}$ & 3.37 & 3.732 \\
$\mathrm{CaO}$ & 62.46 & 77.496 \\
$\mathrm{MgO}$ & 1.33 & - \\
$\mathrm{K}_{2} \mathrm{O}_{3}$ & 0.48 & - \\
$\mathrm{Na}_{2} \mathrm{O}$ & 0.24 & - \\
$\mathrm{TiO}_{2}$ & 0.37 & 3.776 \\
$\mathrm{Sulphur}$ content as $\mathrm{SO}_{3}$ & 2.25 & - \\
$\mathrm{MnO}_{2}$ & - & 7.541 \\
& & \\
\hline
\end{tabular}

\subsection{Mix Proportion and Sample Preparation}

In this work, the nano magnesium oxide is added to the cement composites with various percentages. The mortar cubes were cast for 1:3 ratio. The water cement ratio used is 0.4 . The specimens for compressive strength and durability testing is cast for $70.6 \times 70.6 \times 70.6 \mathrm{~mm}$. The specimens for the study of photocatalytic property was cast for $12 \mathrm{~mm}$ diameter and $5 \mathrm{~mm}$ height. the specimen for RCPT test is cast for $100 \mathrm{~mm}$ diameter and $50 \mathrm{~mm}$ height. The tiles cast for the size of $250 \mathrm{~mm} \times 250 \mathrm{~mm} \times 16 \mathrm{~mm}$. The specimens cast were cured for about 7 days and 28 days. The cast mortar cubes were tested for its compressive strength, water absorption test, Rapid chloride permeability test and durability test for acid attack. The casted mortar cubes were shown in fig. 1 and fig.2. Table III shows the description of samples in the work.

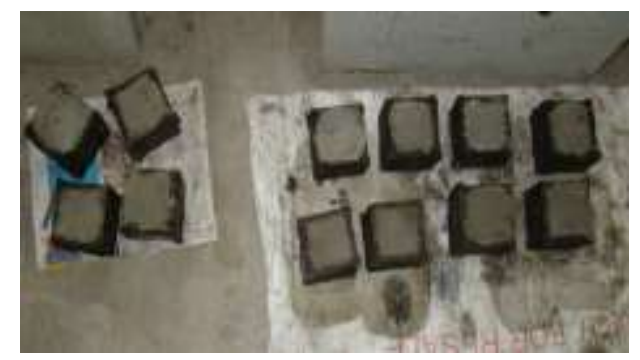

Figure 1 Casting of mortar cubes 
An Experimental Investigation on the Photocatalytic Behavior and Durability Aspects of Nano Magnesium Oxide Incorporated Cement Composite

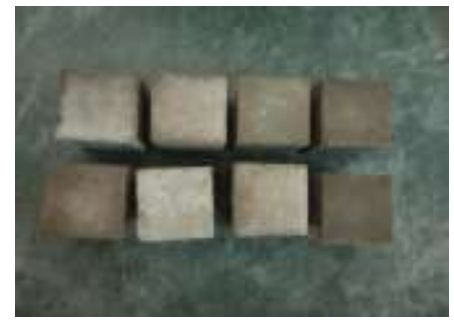

Figure 2 Cast mortar cubes

Table 3 Description of samples in this work

\begin{tabular}{|lll|}
\hline Notations & & Description \\
C-0 & - & Conventional specimen \\
NM & - & Nano magnesium oxide incorporated \\
Numbers & - & Specimen \\
\hline
\end{tabular}

\subsection{Evaluation of Compressive Strength}

The compressive strength is tested for the cubes of size $70.6 \mathrm{~mm} \times 70.6 \mathrm{~mm} \times 70.6 \mathrm{~mm}$. The cubes were demolded after 24 hours and then immersed in the water for 7 days and 28 days. After curing, the cubes were allowed to dry. The loads were applied axially at a uniform rate and the maximum load at the failure was noted. In this work, cement was replaced by GGBS at $30 \%$ to provide better durability. The mortar cubes were casted for various percentage of nano magnesium oxide such as $2 \%, 4 \%, 6 \%, 8 \%$ and $10 \%$. The test results were taken at 7 and 28 days and the results were then compared with the conventional specimen.

\subsection{Photocatalytic Degradation}

\subsubsection{Self Cleansing Property- Degradation of Dye Solution}

After curing the samples were tested for photocatalytic degradation. The degradation of dye solution is studied on the samples and on the tile specimens. The organic pollutant used is methyl violet dye solution. The photocatalytic degradation is studied for $2 \%, 4 \%$ and $10 \%$ nano magnesium oxide incorporated cement composites. The sample is allowed to immersed in a beaker containing $20 \mathrm{ppm}$ of dye solution. Then the beaker with sample is kept under visible light. The sample at $\mathrm{t}=0, \mathrm{t}=60$ mins and $\mathrm{t}=120$ mins were shown in fig. $3 \mathrm{a}, 3 \mathrm{~b}$ and $3 \mathrm{c}$ respectively. The readings were taken for every 30 minutes till the colour of the dye turns colourless. A small amount of the solution is taken and it is subjected into curvet and inserted into the UV-visible spectrophotometer. The readings show the absorbance and the wavelength. The graphs show about the rate of change of degradation with respect to various percentages.

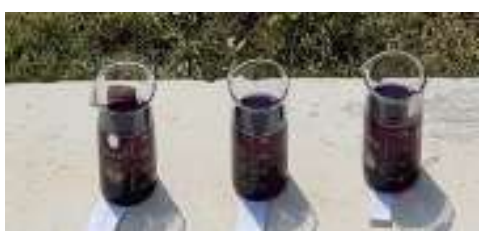

(a)

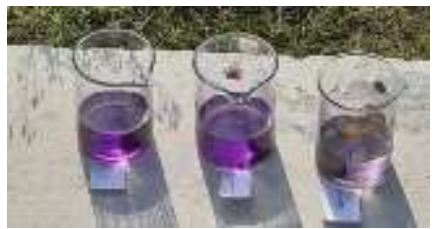

(b)

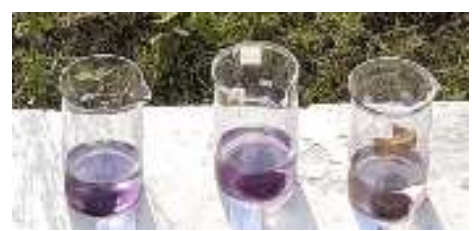

(c)

Figure 3 Photocatalytic degradation at a) $t=0 \operatorname{mins} b) t=60 \operatorname{mins}(c) t=120 \operatorname{mins}$

The photocatalytic degradation is also studied in tile specimen for the increased ppm of about $100 \mathrm{ppm}$ by taking $10 \mathrm{mg}$ per $100 \mathrm{ml}$. the samples were then observed under sunlight and 
complete degradation is achieved. Then the samples were again subjected to an increase ppm of about $500 \mathrm{ppm}$ by taking $0.25 \mathrm{~g}(250 \mathrm{mg})$ in $500 \mathrm{ml}$. Then the solution is applied on the surface of the tile and exposed to sunlight. The complete degradation of dye is observed after a day of exposure to sunlight. Again, the same tile specimen is then subjected for the increased concentration of dye solution. The concentration is increase and then the specimen is again exposed to sunlight. After 2 days of exposure the concentration is reduced and the degradation is done efficiently as shown in fig.4. The conventional specimen also shows little amount of degradation.

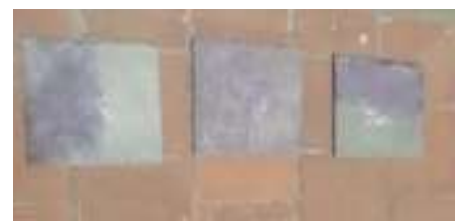

(a)

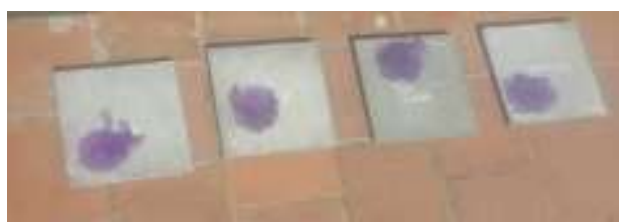

(b)

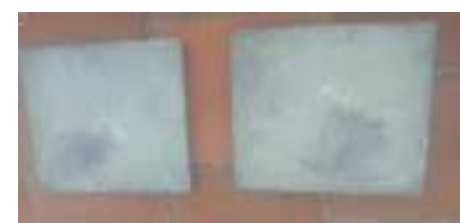

(c)

Figure 4 Photocatalytic degradation of dye in tile specimen at a) $500 \mathrm{ppm}$ b) concentrated ppm (c) after degradation

\subsubsection{Degradation of Gaseous Pollutant}

This method is an approximate method, which uses a fresh water kit to identify the presence of nitrate and nitrite particles in water. Hence this method is adopted to study about the photocatalytic degradation of vehicular emission by nano magnesium oxide incorporated tile specimen. The cast tiles are allowed to keep in a one-sided open container which is covered by glass or with glass sheets which can be easily removable. Then the gas emitted from vehicle is allowed to pass into the air tight container by making an intrusion or a hole on the container or on the glass sheet. The glass sheet is provided and packed in such a way to avoid leakage. The whole setup is then allowed for vehicular emission by connecting with hose. After gas is allowed to pass for few minutes the hose is removed from the vehicle and the other end of the hose is immediately sealed to avoid leaking of gases. Then the whole setup is kept under sunlight to study about the photocatalytic degradation. The gas is allowed to pass into the setup for twice or thrice a day with equal intervals. After 2 to 3 days of exposure to sunlight the samples are taken and their surface is cleansed out by distilled water and the run-out water from every specimen should be collected separately.

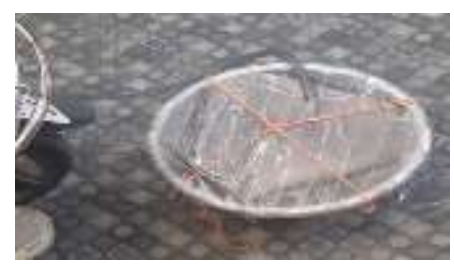

(a)

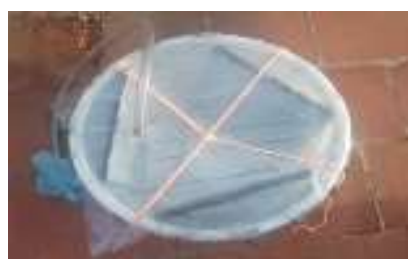

(b)

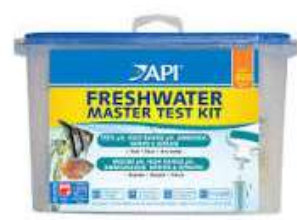

(c)

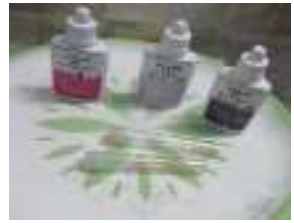

(d)

Figure 5 (a) Airtight setup subjected to vehicular emission (b) Sunlight exposure (c) Freshwater master kit (d) nitrite and nitrate testing solution

\subsection{Water Absorption Test}

The water absorption test is done to evaluate the porosity of the cement mortar cubes. Because the pores influence the water absorption by capillary action. The water absorption test is done for both the mortar cubes and the tile specimen. After the specimens were cast and cured for 28 days, the water absorption is determined for both the control mix and nano magnesium oxide incorporated mortar cubes. The test is conducted as per ASTM D570 standard. Initially the specimen to be tested is set into oven at $110^{\circ} \mathrm{C}$ for 24 hours and then allowed to cool at room 
temperature for 6 hours. The weight is taken as initial dry weight $\left(\mathrm{W}_{\mathrm{D}}\right)$. Then the specimens are immersed in water for 24 hours. Then the moist weight is noted $\left(\mathrm{W}_{\mathrm{S}}\right)$

$$
\mathrm{W}_{\mathrm{ab}}(\%)=\frac{\text { final weight }\left(\mathrm{W}_{\mathrm{D}}\right)-\text { initial weight }\left(\mathrm{W}_{\mathrm{S}}\right) \times 100}{\text { Initial weight }\left(\mathrm{W}_{\mathrm{S}}\right)}
$$

\subsection{Ultra Sonic Pulse Velocity Test}

It is a technique used to evaluate the strength of concrete as well as mortar cubes without destruction as per ASTM C597-16. It is used to identify the uniformity and relative quality of concrete. It is also used to identify the presence of voids and cracks and to find out the effectiveness in crack repairs. The two probes were used for the application of pulse waves generated by electro- acoustical transducer. The probes are held at opposite side of the mortar cubes, where the ultrasonic waves are produced and the other side detect the signal travelled through the cement mortar. The speed of the wave which travelled through the mortar cube (70.6) is measured by a digital indicator.

The pulse velocity $(\mathrm{V} \mathrm{km} / \mathrm{s})=\mathrm{L} / \mathrm{T}$

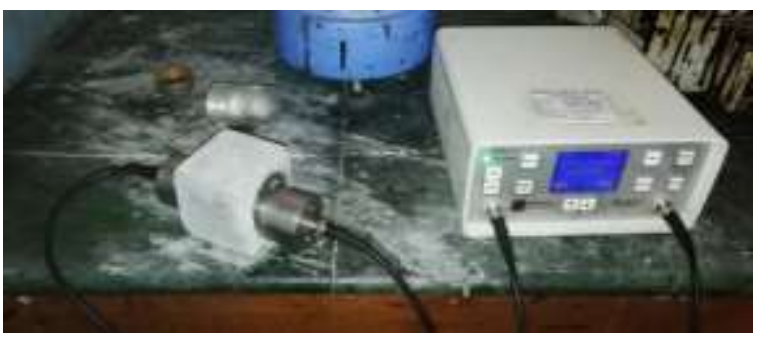

Figure 6 Testing of ultra-sonic pulse velocity

\subsection{Rapid Chloride Permeability Test}

The rapid chloride penetration test is used to evaluate the resistance of concrete to chloride ions. The test is done as per ASTM C1202. The test sample cast is about100 mm diameter and 50 $\mathrm{mm}$ in height. The casted cylindrical cubes were shown in fig.6a. the samples under RCPT testing was shown in fig $6 \mathrm{~b}$. A voltage of about $60 \mathrm{~V} \mathrm{DC}$ is maintain across the ends of the sample throughout the test. One lead is immersed in a $3.0 \%$ salt $(\mathrm{NaCl})$ solution and the other in a $0.3 \mathrm{M}$ sodium hydroxide $(\mathrm{NaOH})$ solution and is carried out for 6 hours.

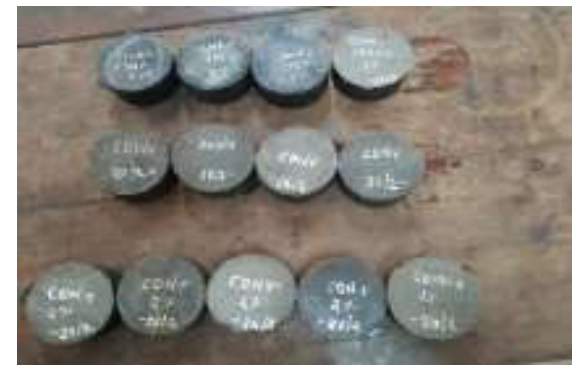

(a)

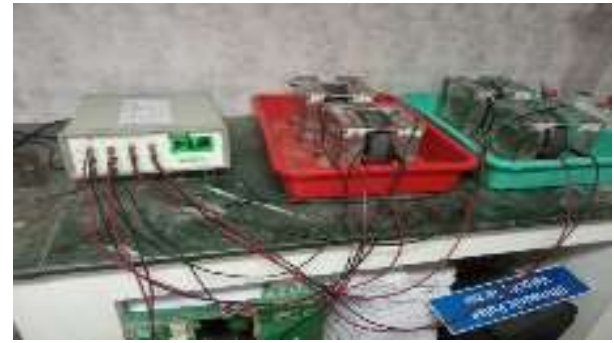

(b)

Figure 7 (a) Cast samples for RCPT test (b) Samples under in RCPT testing

\subsection{Acid Attack Test}

The casted mortar cubes are subjected to the durability test for acids such as hydrochloric acid and Sulphuric acid, nitric acid and magnesium sulphate solution. The standard solution is prepared by using the acid at $5 \%$ concentration with distilled water. To prepare $100 \mathrm{~g}$ of $5 \%$ 
concentrated acid solution, $5 \mathrm{~g}$ of concentrated acid is added by weight for every $95 \mathrm{~g}$ of distilled water. The cubes after subjected to 28 days of curing are weighed and is taken as initial weight (W0) and immersed in the acid solution. The acid solution periodically replaced at an interval of 30 days. The test is done for a period of 60 days and the final weight (W1) is noted. The compressive strength of the specimens subjected to acid attack is also noted.

\subsection{Flexural Strength of Tiles}

Flexural strength is defined as the maximum stress at the outermost fibre on either the compression or tension side of the material. High flexural strength is important for stressbearing, when high pressure/stress is exerted on the material. The tiles of $250 \mathrm{~mm} \times 250 \mathrm{~mm} \times$ $16 \mathrm{~mm}$ size are tested for flexural creep with two opposite edges simply supported and the other two free. These tiles are made to rest on $12 \mathrm{~mm}$ diameter high carbon steel bars placed at 200 $\mathrm{mm} \mathrm{c} / \mathrm{c}$. These tiles are subjected to a central line load through $12 \mathrm{~mm}$ diameter high carbon steel bars parallel to the simply supported edges. The cast tile is tested for its flexural strength. The bearing surface of the supporting and loading rollers-ball are kept wiped and cleaned. Any loose materials found are remove from the surface of the specimen. The specimen should be placed in such a manner that the load should be applied to the upper most surface along two lines spaced 20 or $13.3 \mathrm{~cm}$ apart. The axis of the specimen should be carefully aligned with the axis of the loading service. The load should be applied gradually until the specimen fails and the maximum load at which it fails should be recorded. Fig 7 (a) \&(b) shows the flexural testing of tile.

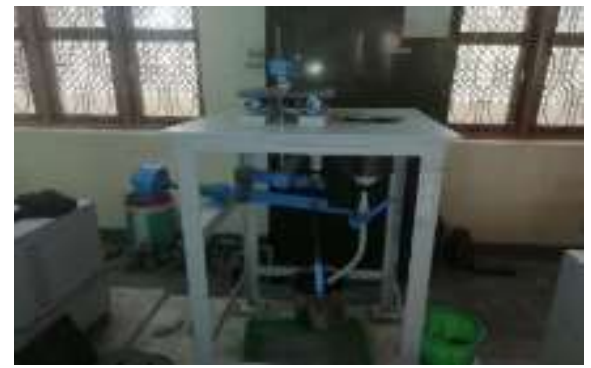

(a)

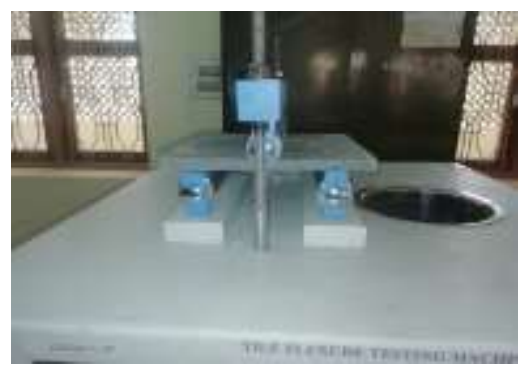

(b)

Figure 8 (a) \&(b) Flexural strength testing of tiles

\subsection{Abrasion Resistance of Tiles}

Abrasion test is done to study about the wear and tear resistance of the tile specimen. The abrasion test is done as per IS 1237-2012. The apparatus consists of a grinding device which consists of horizontally smooth grinding disc. The wear is determined by the measuring instrument before and after the abrasion of the specimen. Then the value is checked by the average thickness obtained from the formula.

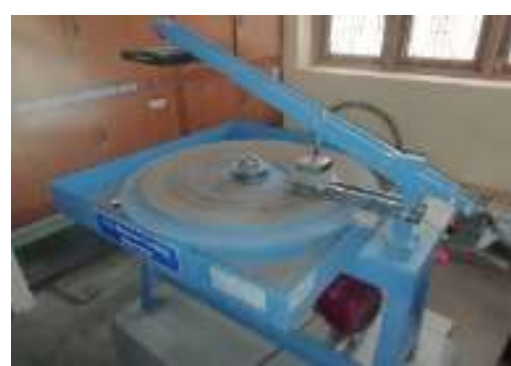

(a)

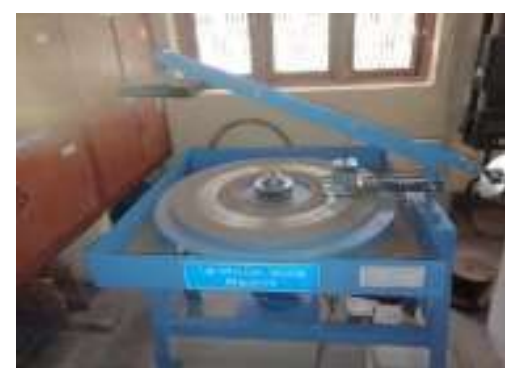

(b)

Figure 9 (a) \& (b) Abrasion testing of tiles 
An Experimental Investigation on the Photocatalytic Behavior and Durability Aspects of Nano Magnesium Oxide Incorporated Cement Composite

\section{RESULTS AND DISCUSSIONS}

\subsection{Compressive Strength}

After 7 days and 28 days of curing the compressive strength for mortar cubes of various percentages were evaluated. The compressive strength is studied for $0 \%, 2 \%, 4 \%, 6 \%, 8 \%$ and $10 \%$. Fig 9. shows the graphical representation of compressive strength. After 28 days of curing the mortar cubes shows increase strength with $2 \%$ and $4 \%$ incorporation of the nano magnesium oxide. It is because the nano magnesium oxide when added in little amount act as a filler imparting strength to the cube.

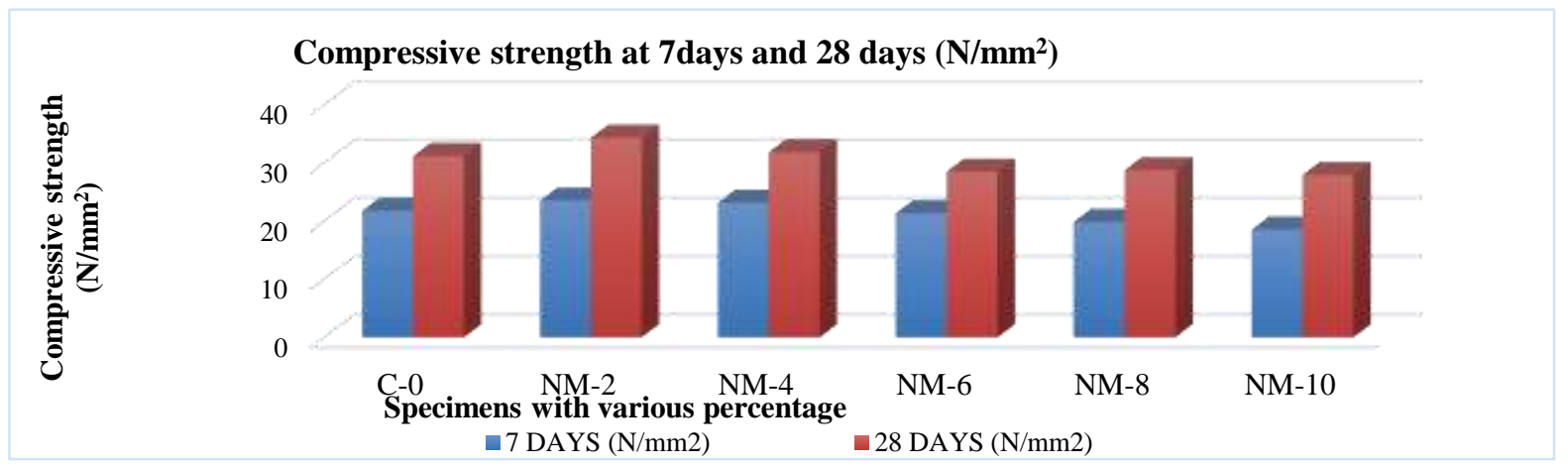

Figure 10 Graphical representation of compressive strength test results

With the addition of nano magnesium oxide, it increases the hydration heat. The reduction of compressive strength is due to the seeding and coating effect of the nano particles on the cement surface. The addition of nano magnesium oxide improves the internal structure by making its microstructure more compact. The hydration reaction of the nano $\mathrm{MgO}$ takes place at the slower rate at early ages. The hydration rate increases with the increase of time and the $\mathrm{Mg}(\mathrm{OH})$ crystals formed as a result of hydration grows up over time and make it denser. But over addition of the nano material causes reduction in strength and leads to failure of the specimen at lower strengths. The increased strength is due to the densification of the microstructure by the nano magnesium oxide as a filler. With the increased nano magnesium oxide, the dilution of cement content occurs and the formation of M-S-H gel and $\mathrm{Mg}(\mathrm{OH})_{2}$ occur which degrades the strength.

From the compressive strength test, it shows that the addition of nano magnesium oxide up to $4 \%$ cannot decrease the compressive strength of the mortar cubes. Hence the durability studies were done for $2 \%$ and $4 \%$ nano magnesium oxide incorporated mortar cubes.

\subsection{Photocatalytic Degradation}

The photocatalytic degradation of $20 \mathrm{ppm}$ methyl violet dye solution is done for various percentage such as $0 \%, 2 \%, 4 \%$ and $10 \%$. The values are quantified by using UV-visible spectrophotometer. After exposing the sample to sunlight, it is periodically checked once in 30 minutes. At time $\mathrm{t}=0$ mins, the spectrum exhibits absorption peak $(\lambda \max =558 \mathrm{~nm}$ with optical intensity $=2.75$ a.u). Gradually the intensity of the peak at $558 \mathrm{~nm}$ is decreased with the increasing exposing time. After 2 hours and 30 minutes the absorbance reduces completely and is found to be 0.1 a.u. the percentage of degradation of methyl violet dye is given by,

$$
\% \text { of degradation }=\frac{\mathrm{C}_{0}-\mathrm{C} \times 100}{\mathrm{C}_{0}}
$$

Where $\mathrm{C}_{0}$ and $\mathrm{C}$ denotes the initial concentration and the concentration of dye after exposing to sunlight respectively. 


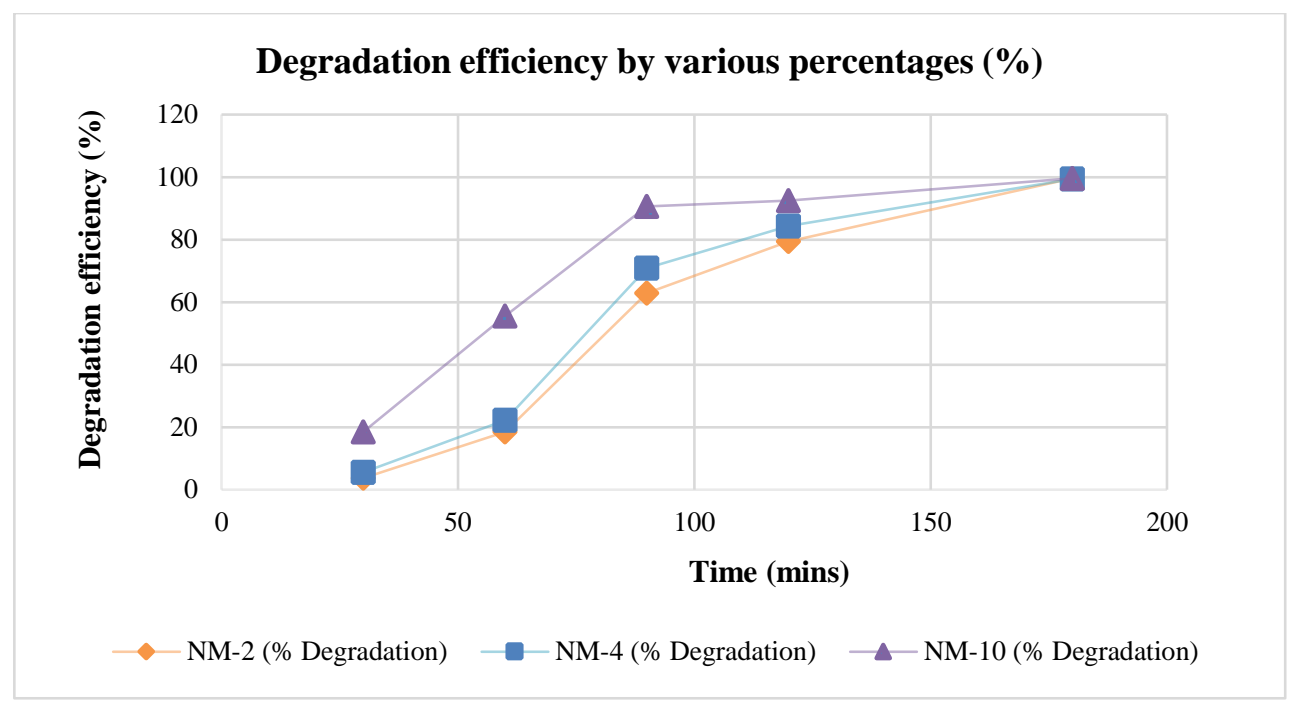

Figure 11 Graphical representation of degradation efficiency by various percentages

The degradation efficiency increases with the increase of nano magnesium oxide. It is due to the increased availability of nano magnesium oxide to create more holes and electrons to activate and speedup the photocatalytic reaction. Below 100 minutes, the $10 \%$ incorporated specimen reaches more than $80 \%$ degradation efficiency. The degradation rate is excellent with the faster rate with the $10 \%$ incorporated specimens.

The degradation of methyl violet dye is studied for $2 \%, 4 \%$ and $10 \%$ nano magnesium oxide incorporated samples. The tile specimens are subjected to $100 \mathrm{ppm}$ of dye solution and the intensity of the dye decreases with the increase of time and the increased exposure to sunlight. All the specimen subjected to $100 \mathrm{ppm}$ of dye solution shows complete degradation. Again, with the increased concentrated of about $500 \mathrm{ppm}$ and then saturated dye solution the sample shows $90 \%$ degradation of the dye.

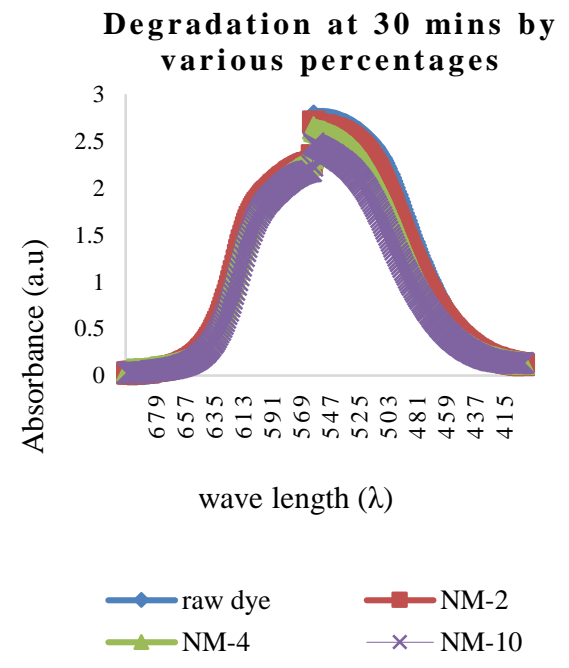

Fig 12a

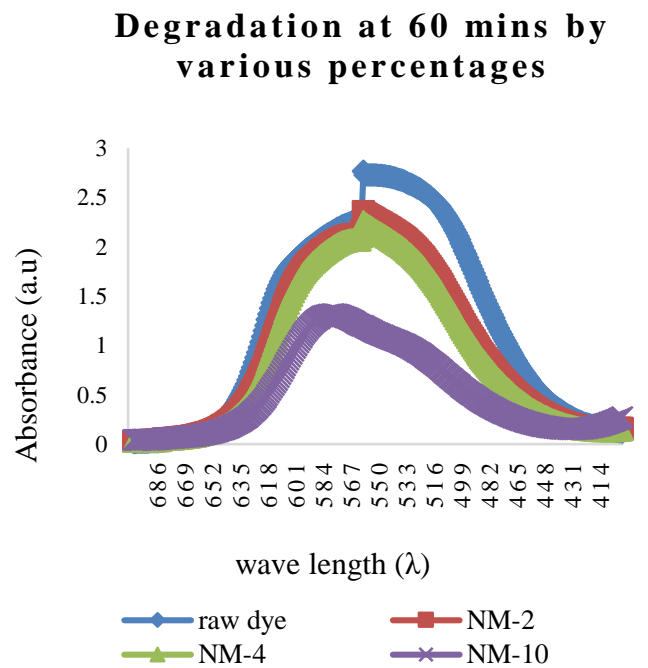

Fig $12 b$ 


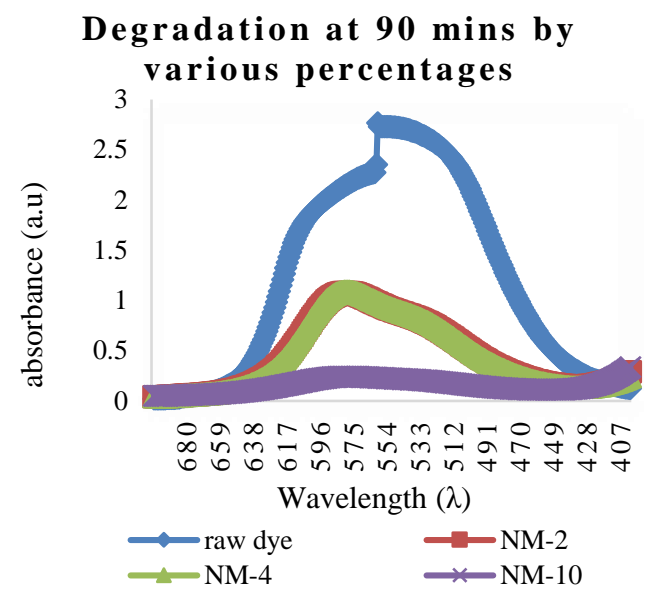

Fig 12c

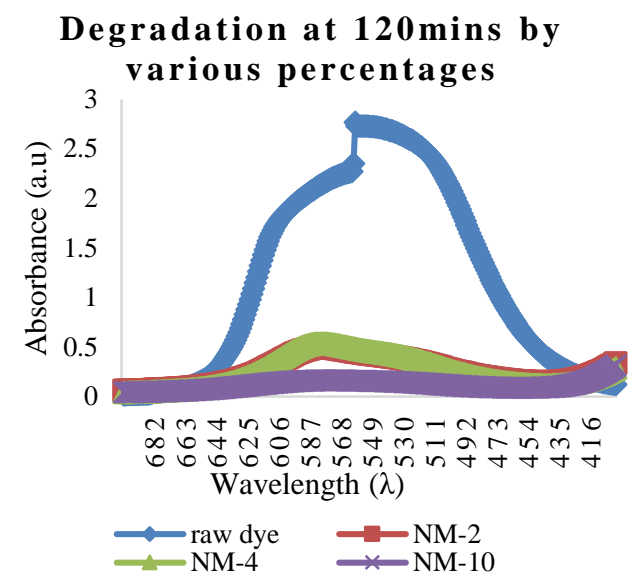

Fig $12 d$

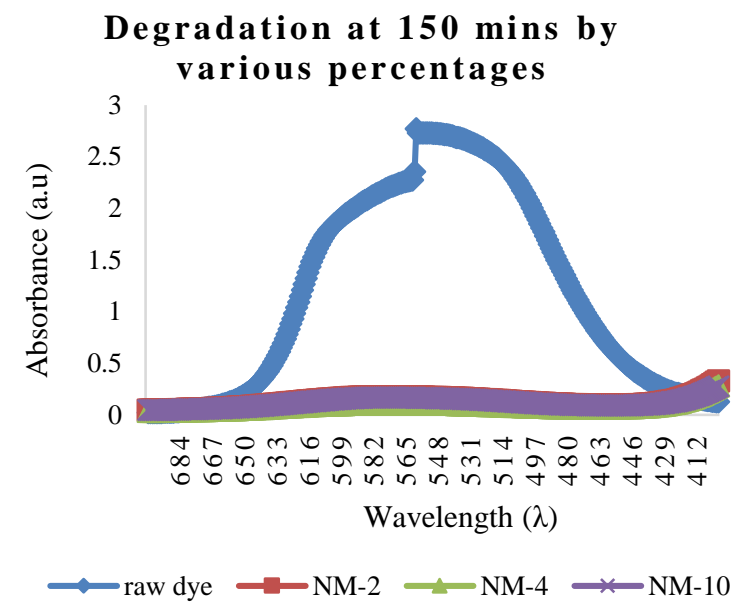

Fig 12e

Figure 12 Graphical representation of degradation by various percentages at a)t $=30 \mathrm{mins}, \mathrm{b}$ ) $t=60$ mins, $\quad c) t=90$ mins, $d) t=120$ mins, e) $t=150$ mins.

The degradation efficiency increases up to a certain level with the increased ppm of dye solution. The slower degradation is may be due to the less availability of nano magnesium oxide on the surface for the photocatalytic reaction. The degradation rate is little faster and degradation efficiency also higher in the $10 \%$ nano magnesium oxide incorporated sample due to the readily available nano magnesium oxide. The humidity also affects the photocatalytic degradation since the reaction needs $\mathrm{H}_{2} \mathrm{O}$ molecule to make $\mathrm{H}^{+}$and $\mathrm{OH}^{*}$ radicals to transfer the charges at the reduction and oxidation sites.

\subsubsection{Photocatalytic Degradation of Gaseous Pollutant}

The tiles subjected to vehicular emission is tested by using API fresh water test kit. The washedout water for every sample is check for the presence of nitrates and nitrites. The presence of the nitrites and nitrates is check by using API fresh water test kit. The test is done by using the solution and the color change should be observed. The water collected from the run out of the various samples are taken in a tube as shown in fig. $5 \mathrm{~d}$ and the nitrate and nitrite solution are added in droplets as mentioned. After that, the color change is check against the API testing chart and the color changes are noted corresponding to ppm. Then the results are noted. 
The results show the conversion of $\mathrm{NO}_{2}$ gas on the adsorption of the surface as $\mathrm{NO}_{2}{ }^{-}$and $\mathrm{NO}_{3}{ }^{-}$by photocatalytic property. It is observed that the conventional tile does not show any change in color for both the $\mathrm{NO}_{2}{ }^{-}$and $\mathrm{NO}_{3}{ }^{-}$conversions. While the nano magnesium oxide incorporated tiles shows considerable change in color and the adsorption increases with the increasing percentage of nano magnesium oxide incorporated tiles. While some tiles show very little change while few tiles show no change and this is because of the formation of M-S-H gels during hydration and non- readily available nano particles on the surface for photocatalysis. But all the surface coated samples shows good photocatalytic property compared to that of the incorporated samples.

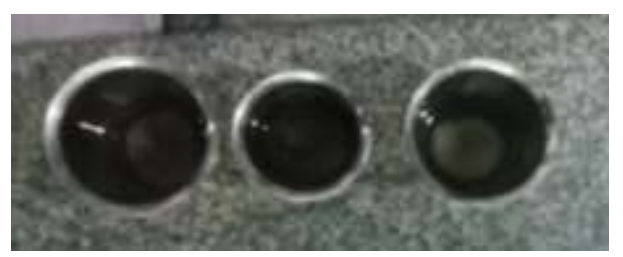

Figure 13 Water samples collected from the tiles

\subsubsection{Adsorption of Nitrite Particles}

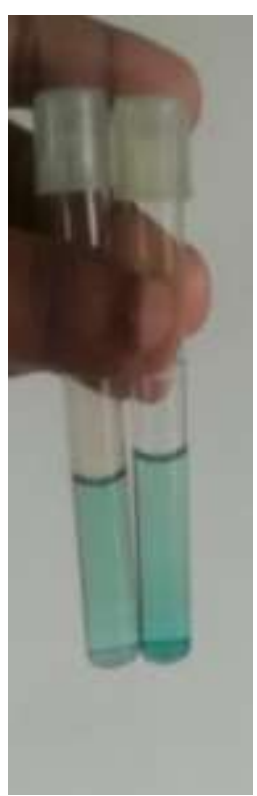

(a)

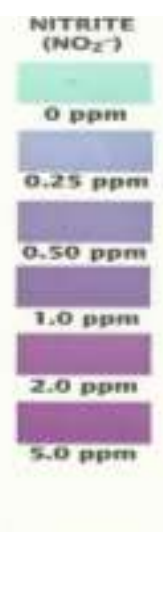

(b)

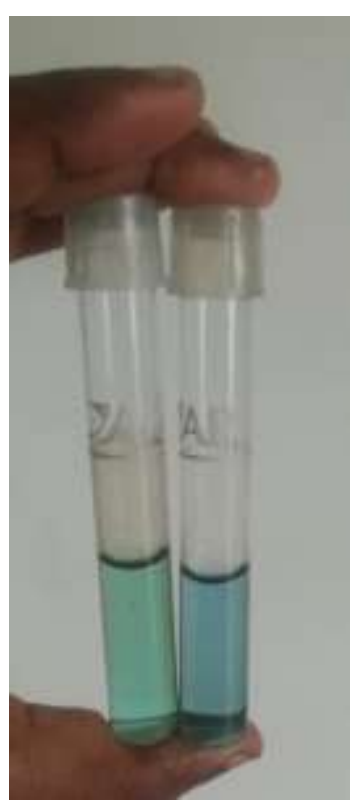

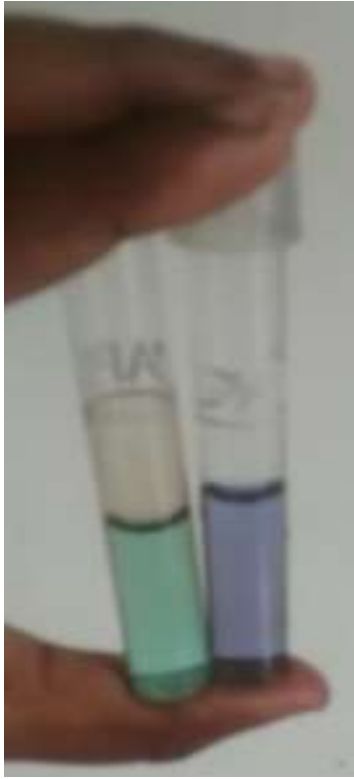

(c)

Figure 14 Change in color due to adsorption of nitrite particles by (a) C-0, (b) NM-2 and (c) NM-4 samples.

Table 4 Adsorption of nitrite particles

\begin{tabular}{|c|c|}
\hline Samples & Adsorption of nitrite particles (ppm) \\
\hline C-0 & 0 ppm \\
\hline NM-2 & 0 to $0.25 \mathrm{ppm}$ \\
\hline NM-4 & 0 to $1 \mathrm{ppm}$ \\
\hline
\end{tabular}

With the exposure to sunlight, the electron-hole pair is generated with the absorption of photons with the energy equal or larger than $\mathrm{MgO}$ bandgap $(5.82 \mathrm{eV})$. The generated electron - hole pair either recombine to create heat or migrate seperately on the surface of the 
photocatalyst to activate the redox reaction. Then the charge transfer occur at both the oxidation and the reduction sites. From the redox reaction of electrons and holes with $\mathrm{O}_{2}$ and $\mathrm{H}_{2} \mathrm{O}$ and $\mathrm{OH}^{-}$, the dominant oxidant of highly active hydroxyl radicals $\left(\mathrm{OH}^{*}\right)$ and hydroperxyl radicals $\left(\mathrm{H}_{2} \mathrm{O}^{*}\right)$. These hydroxyl radical ions then react with the $\mathrm{NO}_{\mathrm{X}}$ in a chain reaction to form nitrate $\left(\mathrm{NO}_{3}{ }^{-}\right)$particles. Again, with the charge transfer, reduction reaction occurs which converts the nitrate into nitrite particles $\left(\mathrm{NO}_{2}{ }^{-}\right)$.

\subsubsection{Adsorption of Nitrate Particles}

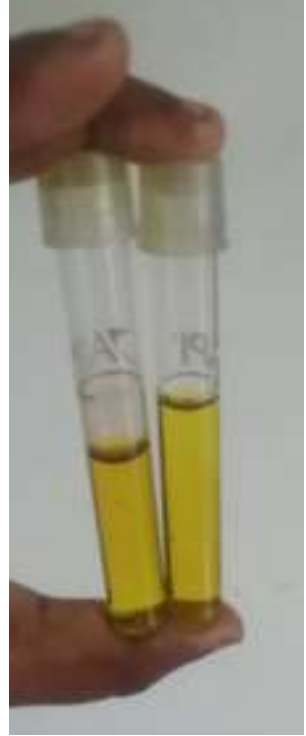

(a)

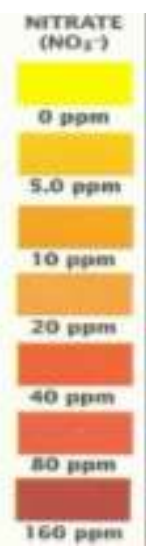

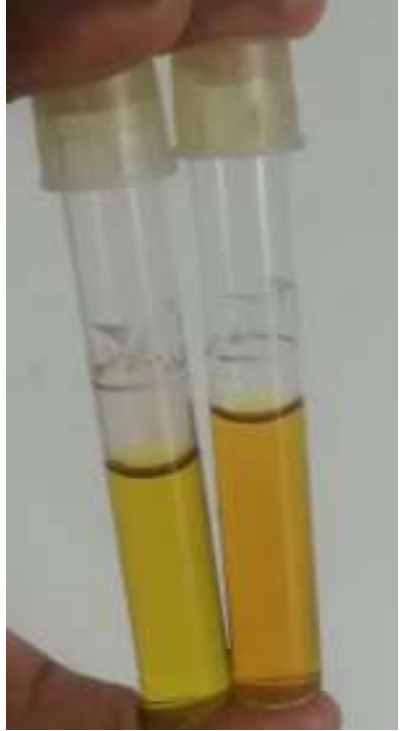

(c)

Figure 15 Change in color due to adsorption of nitrate particles by (a) C-0, (b) NM-2 and (c) NM-4 samples.

Table 5 Adsorption of nitrate particles

\begin{tabular}{|c|c|}
\hline Samples & Adsorption of nitrate particles (ppm) \\
\hline C-0 & 0 ppm \\
\hline NM-2 & 0 to $10 \mathrm{ppm}$ \\
\hline NM-4 & 5 to $20 \mathrm{ppm}$ \\
\hline
\end{tabular}

The highly active hydroxyl radicals $\left(\mathrm{OH}^{*}\right)$ and hydroperxyl radicals $\left(\mathrm{H}_{2} \mathrm{O}^{*}\right)$ which are formed by the redox reaction reacts ith the gaseous pollutant such as $\mathrm{NO}$ and $\mathrm{NO}_{2}$ and to form nitrate $\left(\mathrm{NO}_{3}{ }^{-}\right)$particles. The following reaction shows how the redox reactions converts the nitrogen oxide into nitrates and nitrites.

$$
\begin{gathered}
\mathrm{NO}+\mathrm{OH}^{*} \longrightarrow \mathrm{HNO}_{2} \\
\mathrm{HNO}_{2}+\mathrm{OH}^{*} \longrightarrow \mathrm{NO}_{2}+\mathrm{H}_{2} \mathrm{O} \\
\mathrm{NO}_{2}+\mathrm{OH}^{*} \longrightarrow \mathrm{NO}_{3}^{-}+\mathrm{H}^{-}
\end{gathered}
$$

The photocatalytic test for the adsorption of gaseous pollutant shows good results with the adsorption of pollution on the surface. The $2 \%$ and $4 \%$ nano magnesium oxide added samples shows an adsorption of 1ppm to $20 \mathrm{ppm}$ for $\mathrm{NO}_{\mathrm{x}}$ gas pollutant. 


\subsection{Water Absorption Test}

The rate of absorption of water in the mortar specimens is tested. It is found that the sample incorporated with nano magnesium oxide shows little reduction in the water absorption rate than the conventional mortar. When incorporated up to $2 \%$ the sample shows a penetration rate of $5.09 \%$ lower than the conventional mortar. While the $4 \%$ nano magnesium oxide incorporated specimen shows a little higher water absorption rate.

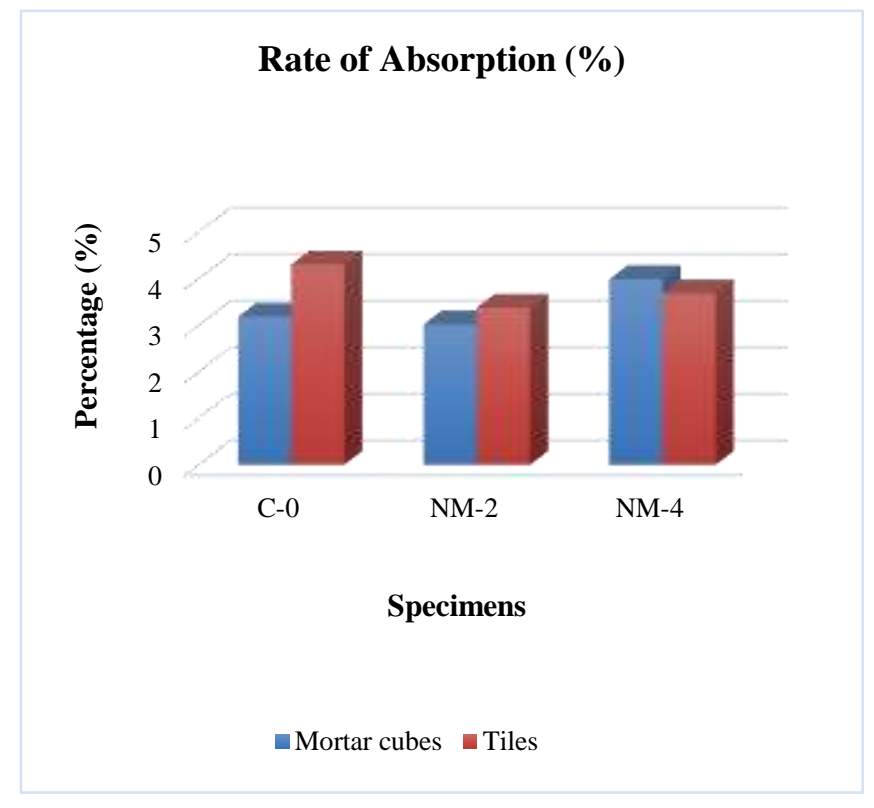

Figure 16 Graphical representation of water absorption test of mortar cubes \& tile specimen

The reduced water absorption rate is due to the denser of the specimen with the incorporation of nano magnesium oxide. With the addition of the nano materials the structure become denser and leads to the reduction in the water absorption rate. With the increased nano magnesium oxide, the water requirement increases which leads to porous cementitious microstructure. Hence the water absorption seems increase with the increased nano magnesium oxide.

\subsection{Rapid Chloride Permeability Test}

Rapid Chloride Permeability Test helps in identifying the quality of the concrete. Lower quality concrete cheats more as the temperature rise is related to the product of the current and the voltage. The lower quality concrete allows greater current to pass through at a given voltage. Thus, produces greater heat energy. This heating leads to further increase in the charge passed. The penetration of chloride ions is considered very low when the total charge passing through the sample is in the range of 100-1000 coulombs. The charge passed through conventional specimen is 1465 coulomb. The amount of current passed in coulomb is measured by rapid chloride permeability test. The nano magnesium oxide incorporated specimen shows $81.5 \%$ increased resistance to the penetration of chloride ions. It shows that the nano magnesium oxide resists the migration of chloride ions.

\subsection{Ultrasonic Pulse Velocity Test}

The ultrasonic pulse velocity test results show that the surface porosity of the specimen and to find out the imperfections and pores in the specimen. From fig.6 it shows the ultrasonic pulse velocity travels much faster than the conventional samples, which shows that the sample is 
An Experimental Investigation on the Photocatalytic Behavior and Durability Aspects of Nano Magnesium Oxide Incorporated Cement Composite

denser and the addition of nano magnesium oxide at $2 \%$ and $4 \%$ reduces the surface porosity which in terms in accordance with the compressive strength of the mortar cubes.

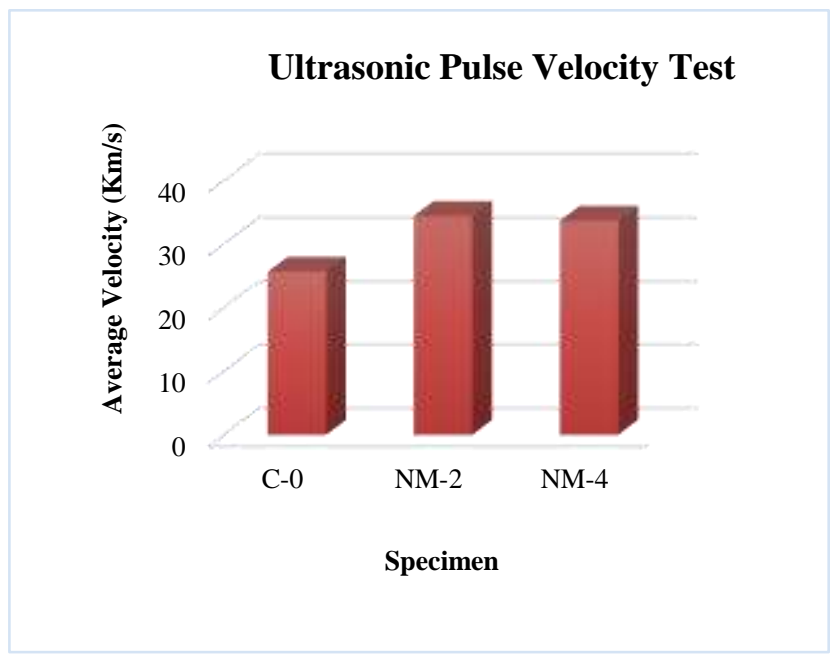

Figure 17 Graphical representation of Ultrasonic Pulse Velocity Test

\subsection{Acid Attack}

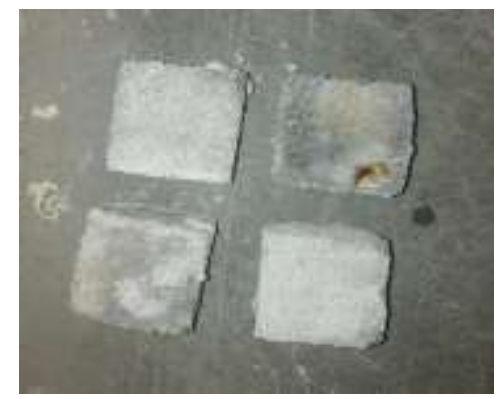

Figure 18 Cubes subjected to sulphuric acid attack

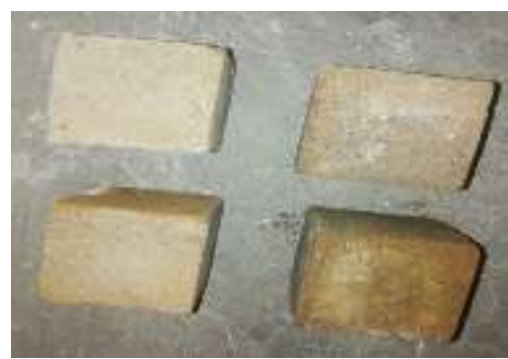

Figure 19 Cubes subjected to Hydrochloric acid attack

The cubes subjected to sulphuric acid attack for 60 days are noted for weight loss and the compressive strength is calculated. The specimens subjected to sulphuric acid attack is subjected to erosion of the sides and corners. The specimen become more porous when subjected to sulphuric acid attack. In sulphuric acid attack the specimen with $2 \%$ nano magnesium oxide added particles shows same strength as that of conventional mortar cubes. The increased strength and resistance in mortar cubes is due to the incorporation of GGBS. With the increased addition of nano magnesium oxide, the strength seems decreasing. The strength decreases with $8.8 \%$ and $31.1 \%$ with the addition of nano magnesium oxide. 


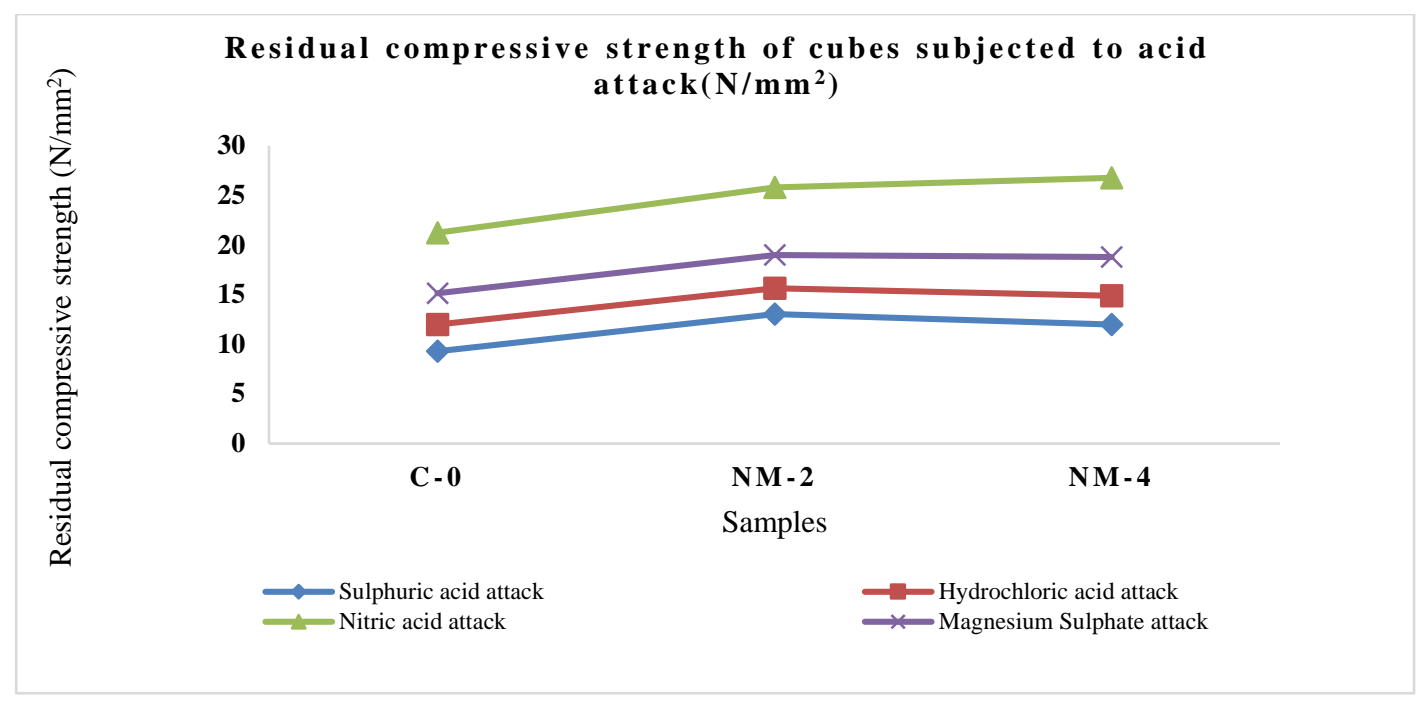

Figure 20 Graphical representation of residual compressive strength of cubes subjected to acid attack

The cubes subjected to hydrochloric acid attack for 60 days are noted for weight loss and the compressive strength is calculated. It is found that with the addition of GGBS and nano magnesium oxide the strength of the mortar cube increases and shows good resistance to chloride attack. With the addition of GGBS and nano magnesium oxide, there is an increased strength of $29.09 \%$ and $20.57 \%$. The weight loss also decreases. Also, the GGBS has good resistance to chloride ingression and nano magnesium oxide mitigates the movement of chloride ions the strength gets increased.

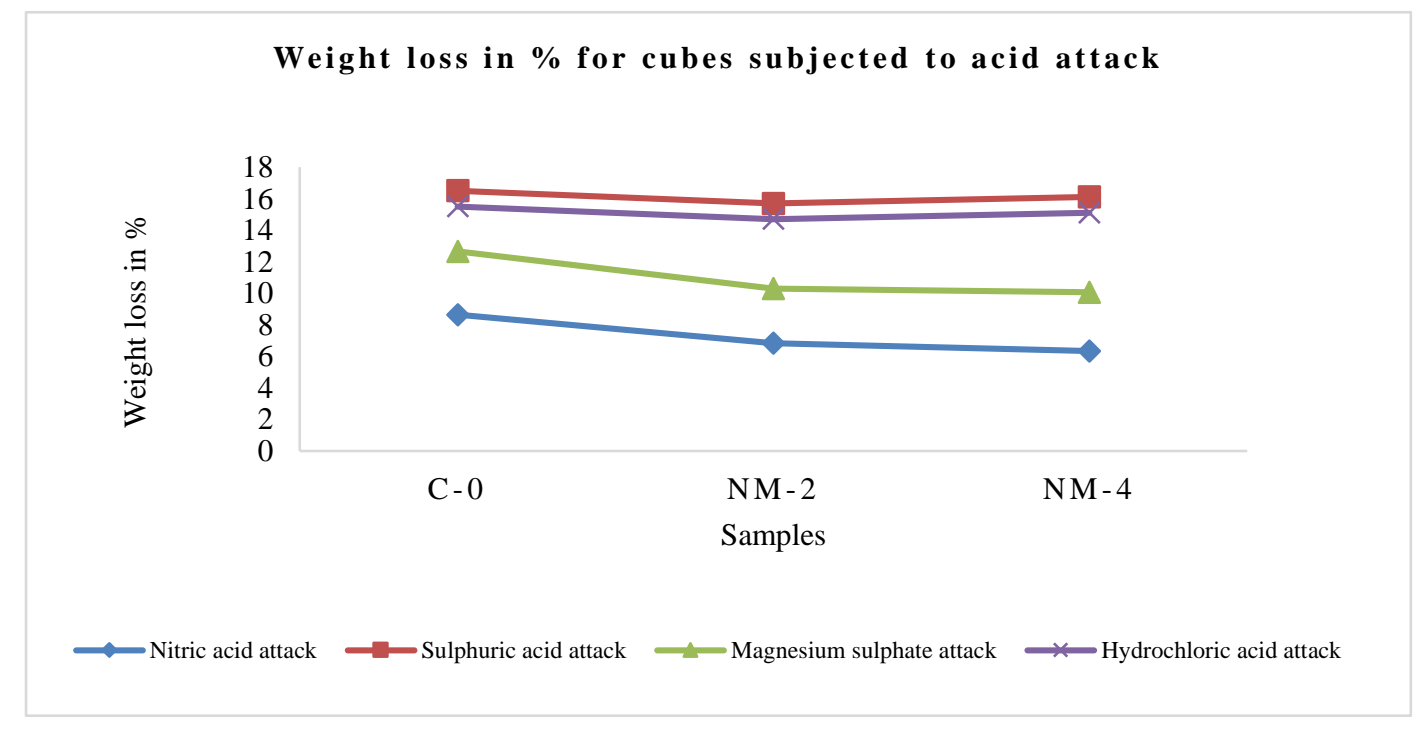

Figure 21 Graphical representation of residual compressive strength of cubes subjected to acid attack

Nitric acid is not as strong as sulphuric acid. But it has its effect when concrete specimen is subjected to a brief exposure. The cubes subjected to hydrochloric acid attack for 60 days are noted for weight loss and the compressive strength is calculated. It reacts with the $\mathrm{CH}$ of the cement paste and forms a soluble calcium nitrate salt which weakens the cement paste and reduces the strength of concrete. The conventional specimens subjected to nitric acid attack shows more attack than the other specimens. The GGBS and nano magnesium oxide added samples shows increased strength with the percentage of $21.50 \%$ and $26.02 \%$. The weight loss is reduced with the addition of GGBS and nano magnesium oxide. 
An Experimental Investigation on the Photocatalytic Behavior and Durability Aspects of Nano Magnesium Oxide Incorporated Cement Composite

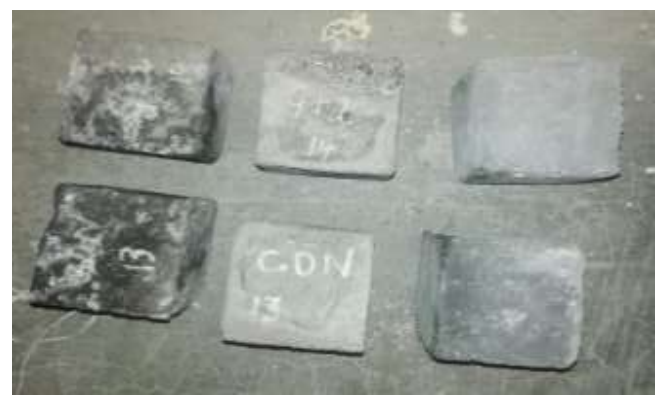

Figure 22 Cubes subjected to nitric acid attack

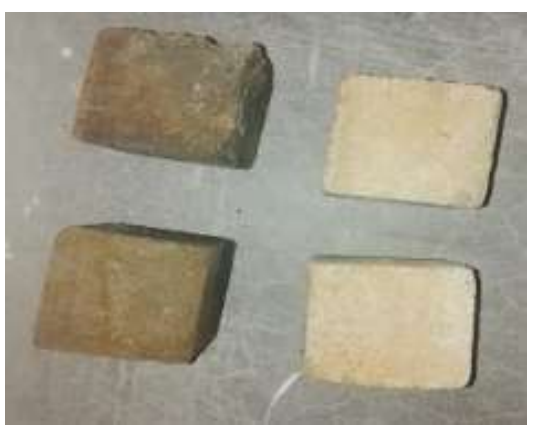

Figure 23 Cubes subjected to sulphate attack

The cubes subjected to sulphate attack for 60 days are noted for weight loss and the compressive strength is calculated. Normally the magnesium oxide incorporated samples shows bad resistance to suphate solutions. Whereas, in case of magnesium sulphate solution it becomes more worse. But with the addition of GGBS it shows good residual strength and reduced weight loss. The residual compressive strength increases with $25.41 \%$ and $23.96 \%$.

\subsection{Flexural Strength of Tiles}

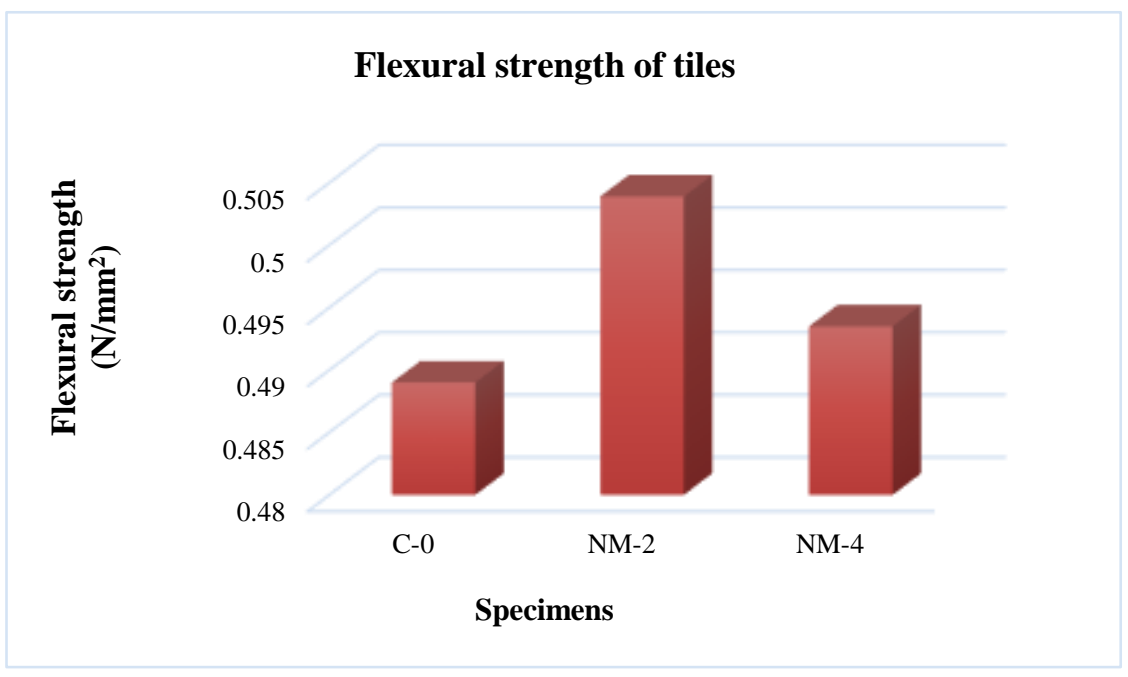

Figure 24 Graphical representation of flexural strength of tiles

With the addition of nano magnesium oxide up to $4 \%$ the flexural strength increases and is slightly higher than that of the conventional specimen, the increase of flexural strength is due to the good binding between cement, GGBS and nano magnesium oxide. The flexural strength increases to $2.8725 \%$ which shows it increased binding property. 


\subsection{Abrasion Resistance of Tiles}

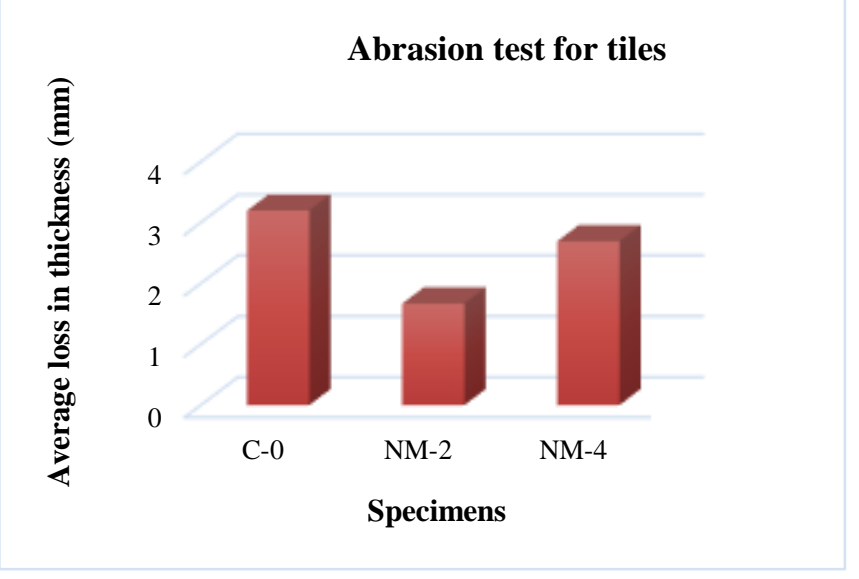

Figure 25 Graphical representation of abrasion test of tiles

With the incorporation of GGBS and nano magnesium oxide the specimen good resistance to abrasion. Hence the specimen can be able to withstand abrasion environment. As per IS $1237-$ 2012, when testing the resistance, the wear should not exceed the following values. Hence the resistance to wear and tear is within the limits for both the conventional and $2 \%$ added nano magnesium oxide incorporated specimen.

\section{CONCLUSIONS}

In this paper, the photocatalytic property of nano magnesium oxide incorporated cement composite was studied along with its mechanical properties and durability aspects.

The sample immersed in the dye solution shows good results to photocatalytic dye solution. This is due to the readily available $\mathrm{H}_{2} \mathrm{O}$ molecule and the presence of nano magnesium oxide on the surface. Hence when the material is coated on the surface or high nano magnesium oxide is readily available on the surface there is a higher degradation rate of the organic pollutant. The photocatalytic degradation of dye solution shows that with the increased addition of nano magnesium oxide, the degradation efficiency increases. The slower degradation in tiles is may be due to the less porous surface and less availability of nano magnesium oxide on the surface for the photocatalytic reaction. The degradation rate is little faster and degradation efficiency also higher in the $10 \%$ nano magnesium oxide incorporated sample due to the readily available nano magnesium oxide. The photocatalytic degradation is affected by the intensity of the light and humidity, since light is needed to excited the electrons from the valence band to the conducted band and the reaction needs $\mathrm{H}_{2} \mathrm{O}$ molecule to make $\mathrm{OH}^{*}$ radicals to transfer the charges at the reduction and oxidation sites. The photocatalytic test for the adsorption of gaseous pollutant shows good results with the adsorption of pollution on the surface. The $2 \%$ and $4 \%$ nano magnesium oxide added samples shows an adsorption of $1 \mathrm{ppm}$ to $20 \mathrm{ppm}$ for $\mathrm{NO}_{\mathrm{X}}$ gas pollutant. When exposed to sunlight the electrons get excited from the valence band to the conduction band and the redox reaction takes place at the surface of the photocatalyst which in turns forms the highly active radicals $\mathrm{OH}^{*}$, which then converts the $\mathrm{NO}_{\mathrm{X}}$ gaseous pollutant to $\mathrm{NO}_{3}{ }^{-}$and $\mathrm{NO}_{2}{ }^{-}$on the surface of the specimen. Also, the photocatalytic property of nano $\mathrm{MgO}$ surface coated specimen shows good performance than the cement incorporated specimen. It is due to the formation of M-S-H gel and the less availability of nano material on the surface the cement incorporated specimens.

The increased strength at $2 \%$ and $4 \%$ is due to the densification of the microstructure by the nano magnesium oxide as a filler. with the increased nano magnesium oxide, the dilution 
An Experimental Investigation on the Photocatalytic Behavior and Durability Aspects of Nano Magnesium Oxide Incorporated Cement Composite

of cement content occurs and the formation of M-S-H gel and $\mathrm{Mg}(\mathrm{OH})_{2}$ occur which degrades the strength. with the increased amount of nano magnesium oxide, the specimens may fail due to increase requirement of water and due to the agglomeration of particles. In water absorption test, due to the uniform distribution and the filler action and denser microstructure formation, the $2 \%$ added sample shows lesser absorption compare to the conventional specimen. The water absorption of the tiles is found within $10 \%$ with the addition of nano magnesium oxide and shows better results with the incorporation of $2 \%$ of nano magnesium oxide as per IS :12372012 and it is found within the limit. In UPV test, the velocity of the waves shows that the specimens are denser and are in good integrity in the $2 \%$ incorporated sample. The densification is due to the nano filler and the pozzolana material. In RCPT test, the nano magnesium incorporated specimen shows very good resistance, because the nano particles act as a filler and also resist the migration of the chloride ions. The increased resistance to chloride ingression is prevented due to the GGBS and nano magnesium oxide present in the sample. In acid attack test, the incorporation of GGBS impart strength and resistance to the ingression of acids. The nano magnesium oxide shows less resistance to magnesium sulphate solution and sulphuric acid. But with the addition of GGBS it shows good strength. The flexural strength of the tiles increased by $2 \%$ incorporated specimen compared to conventional specimen. It decreases with the further increase of nano magnesium oxide. It shows that the binding property increases with the nano filler and the GGBS. The abrasion resistance for both the conventional and the $2 \%$ and $4 \% \mathrm{NM}$ incorporated tiles shows better performance and is within the limit as given by IS 1237:2012.

Hence from this experimental work, it shows that nano magnesium oxide shows good photocatalytic property by degrading both the organic pollutant and the gaseous pollutant. The photocatalytic property of nano $\mathrm{MgO}$ surface coated specimen shows good performance than the cement incorporated specimen. It is due to the formation of $\mathrm{M}-\mathrm{S}-\mathrm{H}$ gel and the less availability of nano material on the surface the cement incorporated specimens. Also, the nano magnesium oxide incorporated cement mortar and tiles performs good in mechanical and durability aspects. Hence the nano magnesium incorporated tile or nano magnesium surface coated tile specimen can be used to reduce pollution. Thus, nano magnesium oxide can be used in building materials preferably as an admixture in cement based or surface coatings for its good photocatalytic property in the degradation of organic pollutant and in the adsorption and conversion of $\mathrm{NO}_{2}$ as $\mathrm{NO}_{2}{ }^{-}$and $\mathrm{NO}_{3}{ }^{-}$particles.

\section{REFERENCES}

[1] Ab Cao, Yajun Zheng et.al., (2019) "Microscale flower-like magnesium oxide for highly efficient photocatalytic degradation of organic dyes in aqueous solution", Royal Society of chemistry, Vol-9, Pg.no 7338-7348.

[2] Abdel Gawwad H.A, Abo El-Enein S.A et.al., (2018) "Synergistic effects of curing conditions and magnesium oxide addition on the physico-mechanical properties and firing resistivity of Portland cement mortar", Construction and Building Materials, Vol-176, Pg.no 676-689.

[3] Amora F et.al., (2018) "Development of Zn-Al-Ti mixed oxides-modified cement phases for surface photocatalytic performance", Case Studies in Construction Materials.

[4] Azam Yousefi, Ali Allahverdi and Parisa Hejazi et.al., (2013) "Effective dispersion of nano $\mathrm{TiO}_{2}$ powder for enhancement of photocatalytic properties in cement mixes", in Construction and Building Materials, Vol-41, Pg.no 224-230. 
[5] Binas V and Papadaki D et.al., (2018) "Study of innovative photocatalytic cement-based coatings: the effect of supporting materials", Construction and Building materials, vol-168, Pg.no 923-930.

[6] Guoa Ming-Zhi et.al., (2018) "Superior photocatalytic NOx removal of cementitious materials prepared with white cement over ordinary Portland cement and the underlying mechanisms", cement and concrete composites.

[7] Huigang Xiao (2019) "Effects of pozzolanic and non-pozzolanic nanomaterials on cementbased materials" in Construction and Building Materials vol- 213.

[8] Jun Chen, Shi-Cong Kou and Chi Sun Poon, (2011) "Photocatalytic cement-based materials: Comparison of nitrogen oxides and toluene removal potentials and evaluation of self-cleaning performance", Building and Environment, vol-46, Pg.no 1827-1833.

[9] Kandiban M, P. Vigneshwaran December (2015), "Synthesis and Characterization of MgO nanoparticles for photocatalytic applications".

[10] Lu Yang, Fazhon Wang et.al., (2015) " $\mathrm{TiO}_{2}$ porous cementitious composites: Influences of porosities and $\mathrm{TiO}_{2}$ loading levels on photocatalytic degradation of gaseous benzene", Construction and Building Materials, vol-150, Pg.no 774-780.

[11] Luigi Campanella, Fabio Borzetti and Luigi Cassar, et.al., (2007) "Photocatalytic Cement: A new approach to environmental protection", Photocatalysis, Environment and Construction Materials.

[12] Magdalena Janus and Kamila Zajac, (2018) "Concretes with Photocatalytic Activity" high performance concrete technology and applications.

[13] Ming Zhi Guo, Chi Sun Poon, (2018) "Superior photocatalytic NOX removal of cementitious materials prepared with white cement over ordinary Portland cement and the underlying mechanisms", Cement and Concrete Composites vol-90, Pg.no 42-49.

[14] Ming-Zhi Guo et.al., (2017), "Photocatalytic NOx degradation of concrete surface layers intermixed and spray-coated with nano- $\mathrm{TiO}_{2}$ : Influence of experimental factors", cement and concrete composites.

[15] Nageswara H. P et.al., (2016) "Synthesis and characterization of nano $\mathrm{ZnO}$ and $\mathrm{MgO}$ powder by low temperature solution combustion method: studies concerning electrochemical and photocatalytic behavior", Nano systems: Physics, Chemistry, Mathematics.

[16] Rajaram M et.al., (2017) "Studies on Optimum Usage of GGBS in Concrete", International Journal of Innovative Science and Research Technology, Volume 2, Issue 5, May.

[17] Singh V.P., Kumar Sandeep et.al, (2018) "Photocatalytic, hydrophobic and antimicrobial characteristics of $\mathrm{ZnO}$ nano needle embedded cement composites", Construction and Building Materials, vol-158, 285-294,

[18] Sivakumar P, Lavanya R et.al., (2016) "Synthesis and characterization of nano $\mathrm{ZnO}$ and $\mathrm{MgO}$ powder by low temperature solution combustion method: studies concerning electrochemical and photocatalytic behavior", in Nano systems: physics, chemistry, mathematics, vol-4, Pg.no 662-666.

[19] V.P Singh, Kumar Sandeep et.al., (2018) "Photocatalytic, hydrophobic and antimicrobial characteristics of $\mathrm{ZnO}$ nano needle embedded cement composites", Construction and Building Materials, vol 158, Pg.no 285-294. 